\title{
Developing a Taxonomy for Digital Platforms - A Conceptual Approach
}

\author{
Chiara Freichel \\ University of Wuerzburg \\ chiara.freichel@uni-wuerzburg.de
}

\author{
Julius Fieger \\ University of Wuerzburg \\ julius.fieger@t-online.de
}

\author{
Axel Winkelmann \\ University of Wuerzburg \\ axel.winkelmann@uni-wuerzburg.de
}

\begin{abstract}
Disruptive companies like Google, Apple, Facebook, and Amazon transform economic and business activity. Faced with their growing economic importance, digital platforms are increasingly adopting essential functions in business and daily life. Discussions of platforms are extended by decisive aspects accompanying this development. Established economic, social, and organization theory show limitations in understanding and describing digital platforms. Researchers need a sophisticated conceptualization of the complex manifold perspectives to fully understand the dynamics of digital platforms and lead the development of platforms in the proper direction. To enable comparability of research results and uniform theory building, this study analyzes existing literature and conceptually develops a comprehensive taxonomy for digital platforms based on multi-faceted approaches. Our taxonomy consists of technological, economic, and socio-cultural perspectives with sixteen dimensions and corresponding characteristics analyzed in detail, which helps scholars classify and articulate the full range of digital platform specifications.
\end{abstract}

\section{Introduction}

The importance of digital platforms, which function as multi-sided markets, continues to grow due to social networks, smartphone app stores, or the so-called sharing economy [1]. Digital marketplaces incrementally meet our demand for digital goods [2]. However, the impact of digital platforms is often underestimated, as they appear virtual, even though not only influencing the digital world. The rise of digital platforms combined with technological innovations, like artificial intelligence or cloud services, results in new business models. By acting as a mediator between buyers and sellers, platforms create an electronic marketplace. A critical effect of these market systems is to reduce search costs, which have to be covered for information about prices and product offers on the market [3]. Furthermore, digital platforms enable faster and more cost-effective delivery of products and services. They also allow end-consumers and companies to be connected more easily. As examples, Uber connects drivers with passengers, LinkedIn supports personal networking, and Amazon offers a convenient way to buy products at a low price.

Digital platforms, as core technical artifacts, complemented by third-party peripheral derivatives, enable organizations to integrate resources into networked business ecosystems. Digital platforms are becoming increasingly complex research objects and differ widely in their configurations in today's industries. Nevertheless, digital platforms' dimensions and characteristics for decoupling different digital platform configurations have not yet been sufficiently explored [4]. Recent work shows a variety of conceptualizations on digital platforms [1], which merely focus on management [5, 6] or economical [7] perspectives of technological platforms. Further authors note that digital platforms show notable differences to these literature streams [8]. A taxonomy focusing on the architectural configuration is built by Blaschke et al. [4]. Authors still demand a scoping and further conceptual clarification of digital platforms [1].

Our taxonomy tackles this issue by organizing the manifold instances and conceptualizations of platforms into a coherent organizational structure. Furthermore, it clarifies theoretical constructs to foster stronger integration between information systems research and organizational and management science. Based on these considerations, we derive the following research questions (RQ) guiding our study:

RQ1: Which dimensions and characteristics can be used to describe digital platforms?

RQ2: How can characteristics be categorized within a taxonomy to distinguish digital platforms?

The study is structured as follows: First, we summarize essential terminological fundamentals. Subsequently, the methodological approach and process 
of the work are presented. This will be applied to answer the research questions in Sections 4 and 5. Finally, we summarize and evaluate the results, point out limitations, and discuss further research possibilities.

\section{Foundations}

The growth of the internet has led to the development of entirely new ways of organizing the economy. This does not easily fit into traditional categories such as firms and markets. Strongly linked with the development of electronic marketplaces, digital platforms can generally be considered as service or technology whose product is the organization of a market [9, 10]. We define an electronic marketplace as one type of digital platform and therefore include corresponding dimensions. Thomas et al. [5] differentiate between digital platforms as market intermediaries and technology systems. From a technical point of view, this work follows the definition of Tiwana et al. [11], in which a digital platform is the extensible codebase of a software-based system that provides a core functionality shared by the modules and interfaces. From an organizational perspective, we define a platform as entity bringing together at least two different actors in the form of business-to-business (B2B), business-to-consumer (B2C) or consumer-to-consumer (C2C).

Matook [12] suggests four views: a) business view: captures the platform's business model and reflects the business rules, both internally and externally; b) transaction view: focuses on technology-supported transactions; c) market service view: specifies the services offered to participants; and d) infrastructure view: provides information and communication technologies for the platform's efficient operation.

With their ability to support new and flexible forms of interorganizational relationships, digital platforms can facilitate highly distributed and automated coordination of activities by enabling a variety of shared resources [1]. Digital platforms potentially lead to relatively low transaction costs in comparison to other forms of coordination between institutions and still offer significant economies of scale and scope. Furthermore, they ensure larger volumes of market transactions to be processed on time. Additionally, network effects have a high impact on success, since the number of individuals or organizations joining a platform determines the value of the platform [3]. The benefits of lower search and coordination costs are reinforced, which reduces overall transaction costs if a large number of actors exists in the market. As a result, according to Bakos [3], platforms can impose high switching costs on their participants, which is generally referred to as the lock-in effect. Once this relationship is established, inter-organizational information systems play an essential role in supporting the relationships.

\section{Methodology}

The present section describes the methodological procedure of this study. We conducted a literature analysis as a basis for the taxonomy development approach, according to Nickerson et al. [14] to classify the properties and core elements of digital platforms. A taxonomy is generally defined as a structure (hierarchy) above the technical terms of a subject area. This paper considers a taxonomy as a form of classification covering essential terms concerning digital platforms. Taxonomies are of particular importance in this context since classifying objects helps researchers and practitioners to understand and analyze complex areas. According to Nickerson et al. [14], the role of taxonomies is well accepted in the research of information systems. A taxonomy is a set of $n$ dimensions, each consisting of at least two mutually exclusive and mutually exhaustive features so that each object under consideration has only one feature for each dimension. The development of taxonomies can be carried out empirically or conceptually [14]. This work follows a conceptual, deductive approach.

For data collection, we conducted a literature analysis. To achieve the goals of this study and to ensure transparency of the search process, suggestions of the authors Webster and Watson [15] for a literature review were considered and the structured literature search according to vom Brocke et al. [16] was applied. At the beginning of the literature search, the scope of our work is defined using the taxonomy by Cooper [13] shown in bold letters in Table 1. Our focus lies on research results, theories, and applications. Goal of the research is the integration of taxonomies of digital platforms with a

Table 1. Defining our Research Scope by Using the Taxonomy of Literature Reviews (following [13])

\begin{tabular}{l|llc}
\hline Dimension & Characteristics & & \\
\hline Focus & Research Outcomes & Research Methods & Theories \\
Goal & Integration & Criticism & Central Issues \\
Perspective & Neutral Representation & Espousal of Position & Applications \\
Coverage & Exhaustive & Exhaustive and Selective & Representative \\
Organization & Historical & Conceptual & Methodological \\
Audience & Specialized Scholars & General Scholars & Practitioners \\
\hline
\end{tabular}




\begin{tabular}{|c|c|c|c|c|c|c|c|c|c|}
\hline Databases & Filter & \multirow{8}{*}{$\begin{array}{l}\text { Search string } \\
\text { ("digital platform*“" OR } \\
\text { "digital market*" OR " } \\
\text { electronic platform*" OR } \\
\text { "electronic market*" OR } \\
\text { "marketplace*") AND } \\
\text { ("taxonom*" OR } \\
\text { "classification*" OR } \\
\text { "typolog*" OR } \\
\text { "categor*") NOT } \\
\text { ("marketing*") }\end{array}$} & \# & \# & & \# & & \# & \multirow{8}{*}{\begin{tabular}{l|c}
$\rightarrow$ & forward \\
and \\
backward \\
search
\end{tabular}} \\
\hline ACM Digital Library & Title OR Abstract & & 1 & 0 & \multirow{7}{*}{$\begin{array}{c}\text { keyword } \\
\text { and } \\
\text { abstract } \\
\text { analysis } \\
+ \\
\text { duplicate } \\
\text { removal }\end{array}$} & 0 & \multirow{7}{*}{$\begin{array}{l}\text { full text } \\
\text { analysis }\end{array}$} & 0 & \\
\hline AIS Electronic Library & Title OR Abstract; Series, Conferences, Journals & & 39 & 17 & & 6 & & 4 & \\
\hline EBSCO BSP & Title OR Abstract; Scholarly (Peer reviewed) Journals & & 412 & 39 & & 11 & & 10 & \\
\hline Emerald Insight & Title OR Abstract; Article & & 176 & 12 & & 3 & & 3 & \\
\hline IEEEXplore & Data Fields; Conferences, Journals, Magazines & & 152 & 8 & & 3 & & 2 & \\
\hline Science Direct & Title, abstract, keywords, Review articles, Research articles & & 63 & 5 & & 1 & & 1 & \\
\hline Web of Science & Topic; Article, Review, Proceedings Paper & & 665 & 28 & & 6 & & 4 & \\
\hline
\end{tabular}

Figure 1. Literature Search Process

specific focus, their critical analysis, and the elaboration of central topics. Furthermore, a neutral presentation and all-encompassing selective coverage of the research area are aimed. The results are organized conceptually by using the methodology of taxonomy development. The target group is composed of specialists from the field of business informatics and practitioners.

The four steps of the literature research, according to vom Brocke et al. [16], are summarized in Figure 1. For a high-quality literature analysis, journals, and papers from renowned conferences of the Basket of Eight [17] and the VHB-Jourqual3 [18], with a rating of C or higher, were used. Since authors use different terms to describe taxonomies and digital platforms, the search term (see Figure 1) covers different concepts. The limitation "NOT ("marketing*")" was made due to the unsuitable results given for the terms "digital market*" and "electronic market*". To ensure consistency, the search in AIS Electronic Library and Emerald Insight was carried out separately in titles and abstracts, since the use of both filters Title and Abstract in IEEE Xplore and Web of Science did not result in search matches. Figure 1 summarizes the numbers of search results. Twenty-nine articles serve as a basis for the analysis.

\section{Classification Approaches}

In this section, different classification approaches of the twenty-nine relevant articles used for digital platforms will be considered. We implemented a concept map according to Webster and Watson [15] in Table 2 to structure our search results. The most important dimensions, as well as characteristics relevant for developing a taxonomy, are discussed within a framework of three perspectives in the following. Since this work is based on the taxonomy development procedure of Nickerson et al. [14], we will also use the terms dimension and characteristic in the following.

\subsection{Technological Perspective}

We consider the taxonomy of Blaschke et al. [4] from a technological perspective. The purpose of their taxonomy is to distinguish digital platforms based on common features within the architectural dimensions. The authors identify the four dimensions infrastructure, core, ecosystem and services. The dimension core has several technical core artifacts, whereas the other dimensions represent the dynamic periphery of the platform components.

Concerning the dimension infrastructure, Blaschke et al. [4] define three types of access to digital platforms: direct, indirect, and open access. Direct access means that the platform owner grants unrestricted access to established digital infrastructure. Indirect access represents limited permission for access to a digital infrastructure by an intermediary, third-party access provider. Open access provides unrestricted access to a digital infrastructure without the need for licenses [4]. Kazan et al. [19] also consider openness for mobile payment platforms and differentiate in detail between direct, indirect, and open access to existing value creation architectures. Payment platforms with direct access to established value delivery architectures can often benefit from industry-specific resources. Payment platforms with indirect access achieve competitiveness through cooperation with third parties, e.g., banking institutions. Platforms with open access to value-added architecture become competitive by providing novel architectures such as blockchain [19].

Regarding the dimension core, Blaschke et al. [4] distinguish the two ways openness of access and openness of resources in which core artifacts can be connected to their periphery in order to promote third-party platform-enhancing derivatives. The basic principle of open access is to stimulate innovation within the platform ecosystem.

Regarding the dimension ecosystem, two central characteristics are distinguished [4]. The private network is a vertically integrated, and self-contained ecosystem that includes a certain selection of private actors who protect their services from unauthorized actors. On the contrary, an allied network is an outward-oriented and open ecosystem that mobilizes various third-party actors accompanying the platform 
Table 2. Concept Map of Search Results

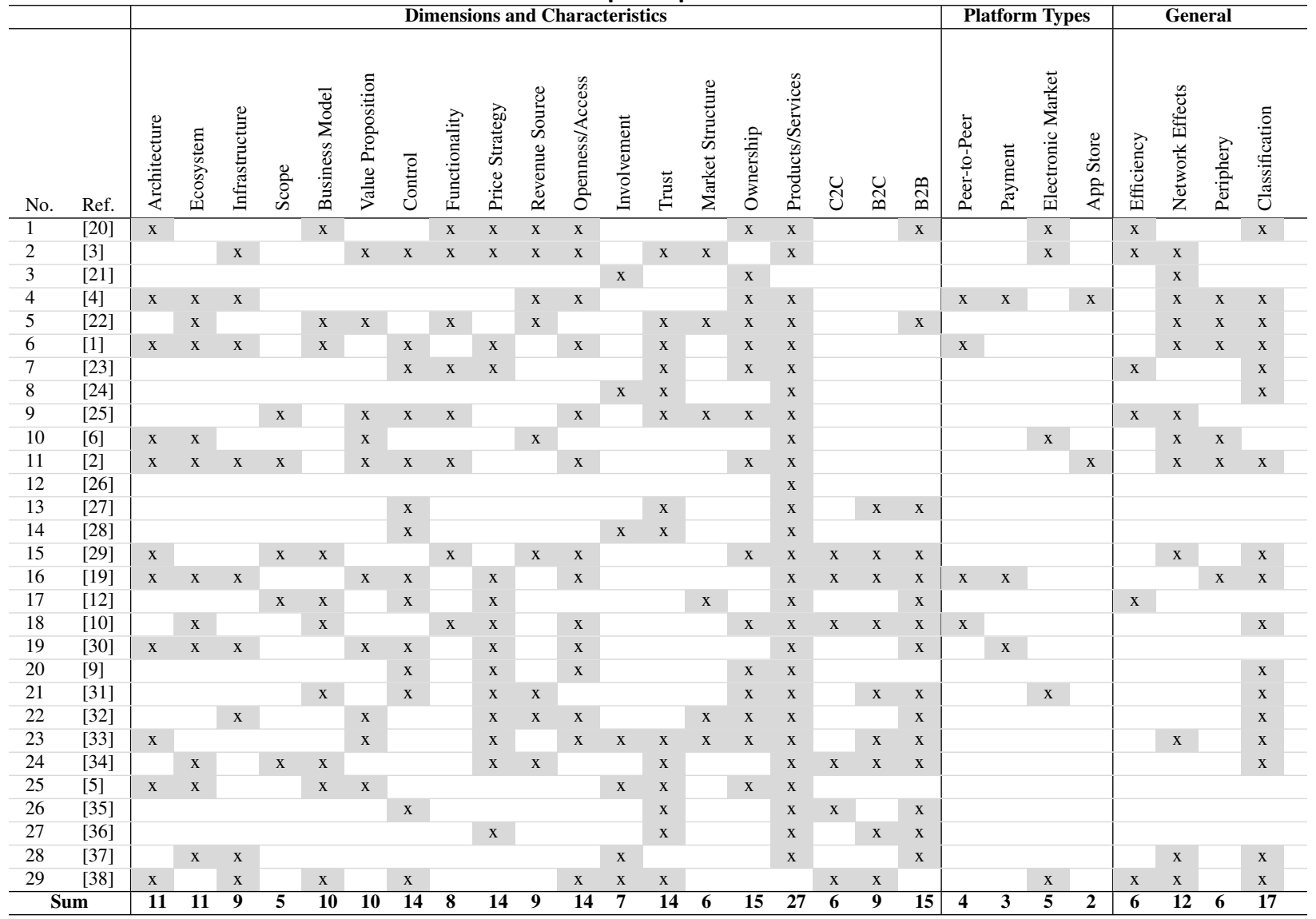

and expanding the capabilities and market range of the common digital platform.

For platform-mediated digital services, there are two different orientations: exchange and design [4]. Digital services focusing on an exchange such as Facebook, PayPal, Uber, or Airbnb, contribute to the reduction of transaction costs in a direct exchange between actors. Design-oriented digital services such as iOS, Windows, or Amazon Web Services should enable third parties to design platform derivatives and enable correspondence between a third-party platform designer and many users of derivatives.

From a technical point of view, Ghazawneh and Henfridsson [2] identified a control dimension and corresponding characteristics. Control of a platform can be either centralized or distributed and is exercised by a single member of the platform ecosystem or by several members [2]. Kazan et al. [19] state that leadership is a permanent challenge for platform operators and that they are required continuously to enforce control.

As next dimension, Ondrus et al. [30] identified openness at the supplier, technology and user levels. According to the authors, multilateral platforms can only be successful if a critical mass of users can join. The provider level thus recognizes the strategic involvement of the key stakeholders providing a platform. The technology level deals with the interoperability of a platform across different technologies. The user level refers to the extent to which a platform discriminates against different customer base segments. According to the authors [30], a platform can be provided either by a single company that vertically integrates all the different resources and competencies required or by some horizontally cooperating companies with specific roles and responsibilities. Established platform providers must first decide on the degree of openness at the provider level, i.e., whether to allow other companies to join. In this respect, Ondrus et al. [30] have identified three strategies: Competition (one company), co-opetition (companies from the same sector decide to cooperate), and cooperation (companies from different sectors work together) to achieve openness. Each strategy at the supplier level leads to different market potential. To achieve a higher market potential, providers can open up the technology layer by enabling interoperability with competing or 
complementary platforms. If a platform is closed at the user level, the users are limited in terms of market potential to the market share of the provider(s). By opening a platform at the user level, additional users of other platforms or users not connected to any platform are able to join.

\subsection{Economic Perspective}

According to Movahedi et al. [10], one of the central topics is the exploration of the different types of digital platforms. Since electronic markets can be classified according to different dimensions, there is a need for a multidimensional classification model. The authors have identified several dimensions, in particular focusing B2B types. The classification dimensions include the type of actors involved in the transactions. In this case, three parties can generally be assumed as the characteristic value: government, businesses, and end-users. In some cases, Movahedi et al. [10] also use the term peer-to-peer to emphasize platform neutrality.

Another dimension is the type of product or service, whose characteristics are vertical and horizontal [10]. Vertical electronic marketplaces focus on the aggregation of supply and demand of products or services in a specific sector. The horizontal marketplace is used for products or services that are common in several different industries. The authors also distinguish between long-term and short-term business relationships as characteristics of the relationship horizon. In addition, a distinction is made between fixed and variable pricing mechanisms concerning price formation. According to Movahedi et al. [10], a marketplace distortion can be divided into hierarchical (distorted) and market-oriented (neutral). In hierarchical markets, a market operator carries out transactions on the marketplace either as a buyer or a seller. Considering the orientation of electronic markets, Standing et al. [33] also state the existence of vertically and horizontally oriented marketplaces. However, they conclude that this distinction lacks clarity. In this respect, Leong et al. [39] distinguish between a classical value-added model, which creates added value by controlling a linear series of activities along a vertical chain of command, and network-centric digital platforms, which are designed based on horizontal cooperation between the users involved. This shows that Leong et al. [39] do not consider classic B2B marketplaces, as they are often found in industry, to be modern digital platforms, compared to the $\mathrm{B} 2 \mathrm{C}$ or $\mathrm{C} 2 \mathrm{C}$ sector. In contrast, market-oriented electronic markets are expected to be impartial. Market operators as third parties do not conduct transactions themselves. In this context, market orientation is divided into buyer-oriented, seller-oriented, and neutral marketplaces. Buyer-oriented platforms are operated by several buyers who join together to aggregate demand. Seller-oriented platforms, as an association of sellers, are characterized in particular by the representation of the interests of suppliers. Neutral, two-way marketplaces are usually operated by an unbiased third party that matches buyers and sellers [10].

Movahedi et al. [10] also include market access in their model, which can either be open and thus allow any buyer or seller market transactions or the marketplace is closed. In the latter case, transactions require membership. Closely related to market orientation is the dimension of market ownership. The buyer or seller side owns and operates the electronic marketplace, or a neutral third party, or consortia, in which several essential market participants of the buyers, sellers, or intermediaries join together. Soh and Markus [32] also include ownership as a core dimension in their approach. The ownership structure can distort the value proposition, product-market focus, and value activities of a platform in favor of the interests of the owner buyer, seller, intermediary. Concerning ownership of electronic markets, Duan et al. [23], however, did not identify significant influence on platform efficiency.

The underlying market structure of a marketplace can be centralized or decentralized [32]. With a centralized market structure, interactions of buyers and sellers are mediated by the platform. In the case of decentralization, the parties contact each other directly to obtain prices and additional product information and to negotiate the terms. The authors Standing et al. [33] also differentiate between ownership and management structures by naming four characteristics. First, private marketplaces as hierarchies operated by individual companies to interact directly with their buyers or suppliers. Second, public marketplaces, which are independently owned and operated horizontally or within a particular industry. Third, consortium marketplaces, which are usually owned by competitive organizations within an industry. Fourth, collaborative electronic marketplaces, where ownership and management are distributed among many participants and in some cases among all members.

The research by Sharifi et al. [31] proposes a method for classifying supply chains with the concept and practice of electronic markets. First, the authors categorize the ownership structure of electronic marketplaces as independent, sector coalition, and private. The difference between these three types is the degree of control exercised by the participants. In the case of an independent platform, the management 
is owned by a neutral third party. Sectoral coalitions, often in the form of joint ventures, consist of groups of companies that come together to achieve mutual benefits. Private marketplaces represent a further characteristic, which are managed by a single company. Suppliers of products and services are asked to satisfy the needs of this individual customer. Furthermore, the authors [31] discuss functionality as a dimension. The functionality requirements involve a platform that allows stakeholders to buy, sell, auction, track, connect, integrate, collaborate, and manage electronic payments in a secure environment. Most electronic marketplaces have combinations of these different functions.

The authors Täuscher and Laudien [34] develop six business model types of digital platforms using cluster analysis. In doing so, they concentrate on marketplace forms that are facilitated by technological advances. One of the business model dimensions is the type of platform technology as a purely web-based or mobile application. The second dimension relevant to the business model of a digital platform is the key activity. Here the authors distinguish between data services, the formation of communities, and the creation and preparation of content. A third dimension is pricing mechanisms, which can be based on a pricing system where the platform provider, the supply or the demand side sets the price. Alternatively, pricing can also result from an auction system or through negotiation between the parties [34]. In this regard, Duan et al. [23] concluded that electronic marketplaces that use a fixed-price transaction mechanism are more efficient.

Another critical dimension is the type of value perceived by the user. This value proposition is the totality of the advantages that a company offers its customers [32]. This can be expressed in price, cost, or efficiency advantages, in emotional or social values for the customer [34]. The emotional value means, for example, a superior user experience, whereas the social value is expressed in the image associated with the use of the marketplace, in the form of interaction with other marketplace participants. In a further dimension of the evaluation system, the authors distinguish between whether the participants evaluate each other, whether the platform provides an evaluation based on standardized metrics, or whether there is no evaluation mechanism.

With regard to transactions on digital platforms, the dimension of the transaction content, which is reflected in the form of products or services, should be mentioned on the one hand. On the other hand, the delivery of the product or service depends on the type of transaction - digital or offline. These two dimensions show whether the marketplace offers physical products, digital products, online services, or offline services.
As a further dimension, it is specified whether the platform offers vertical or horizontal market integration [34]. Besides, the type of user segments shows which participants the marketplace primarily connects. These include the characteristics $\mathrm{C} 2 \mathrm{C}, \mathrm{B} 2 \mathrm{C}$, and $\mathrm{B} 2 \mathrm{~B}$. The geographical reach of digital platforms can be divided into global, regional, and local [34].

About the dimension revenue stream, marketplaces are differentiated between the commission model, the subscription model, the advertising model, and the sale of services [34]. Pricing is characterized by fixed price, market price, or differentiated pricing. Sources of income can be considered to be sellers on the supply side, buyers on the demand side, or a third party [34]. Further characteristics of a business model are Web 2.0 competence and the maturity of the revenue model. Both can be classified as low, medium, and high [29]. A high-value offer allows for content and network functions as well as sales within the platform. In their model for evaluating marketplaces, Alt et al. [20] have used four criteria to define the marketplace position in concrete terms. In homogeneous platforms, the products offered have functional equivalence from the customers' point of view. Open marketplaces are accessible to all participants, and there are no barriers to market entry or exit. The main focus of an electronic marketplace can be the specialization on certain products, processes or industries. With regard to products, the authors [20] distinguish between direct and indirect goods.

Since digital platforms are profit-oriented companies, the profit model is particularly important for economic sustainability [20]. For platform providers, the question thus arises about whether and, if so, how they should demand differentiated access and usage fees from the participating user groups [9]. Concerning B2B platforms, authors [20] consider different revenue-generating characteristics for the revenue model. On the one hand, they name membership fees as fees for the general right to participate in the marketplace for a certain period, e.g., per month. There are also user fees, which are expressed in charges for additional services. These can be divided into availability fees, e.g., for databases, and processing fees for the use of information services. Transaction fees are another way to generate revenue. In case of successful coordination of supply and demand, a commission can be charged in the form of a percentage of the sales price or cost savings. In this context, a booking fee for discontinuing supply or demand is also possible. Advertising revenue or software licensing represents further revenue models for electronic marketplaces. According to Alt et al. [20], one dimension is also formed by transaction services, which occur as an 
allocation process both statically, in the form of catalogs, and dynamically, through auctions.

\subsection{Socio-cultural Perspective}

In addition to the typical evaluation criteria for designing information systems such as user acceptance or system quality, the attractiveness of a platform depends as much on its technical performance as on the intended network effects and intangible aspects such as trust $[1,33]$. Trust and risk perceptions can account for a share of $20 \%$ for the purchase decision on electronic markets [35]. Therefore, trust between the parties and party risk have considerable effects on platforms [35]. The exchange of information via the Internet can entail risks that are either caused by functional deficiencies or security problems in information and communication technology systems (system-dependent uncertainty) or can be explained by the behavior of actors involved in online transactions (transaction-specific uncertainty) [27]. In this regard, Fairchild et al. [25] identified that all of the marketplaces they studied use privacy statements to ensure security among the traders. According to the authors, this could contribute to trust and, thus, to the platforms' success. Security mechanisms are, therefore, crucial in online marketplaces. These can act as quality signals that help buyers to reduce the probability of problematic transactions with sellers [36].

Another dimension concerning the classification of digital platforms is the commitment examined by $\mathrm{Yu}$ and Ramaprasad [37]. They mention four different types. Platform engagement is defined as the degree of voluntary allocation of personal, cognitive, emotional, and behavioral resources. The former refers to a user's time and energy spent on a platform related interaction (product or content), other users, or the platform itself. Consequently, the platform engagement can be classified as a multidimensional concept according to the two main aspects of resource and object, derived from the resources the user deploys in his engagement. Furthermore, the authors [37] name cognitive engagement. This forms the degree of mental absorption of a user into a central object in a platform-related interaction. Emotional engagement as a third characteristic is the degree of affective devotion and sense of belonging of a user in a platform-related interaction. Behavioral binding is the degree of a user's action in a platform-related interaction. Eigenraam et al. [24] have developed a taxonomy of digital customer retention practices. These include approaches to customer retention from a $\mathrm{C} 2 \mathrm{C}$ perspective such as blogs, recommendations to friends, from a B2C perspective watching videos and signing up for updates, and from a $\mathrm{C} 2 \mathrm{~B}$ perspective writing reviews or submitting suggestions.

Drivers for the continuous development of the platform include usability and trust [30]. Some digital platforms offer opportunities, such as supporting new ways of interaction within communities or mediated co-creation [1]. This refers to the participation of consumers and producers in the creation of value on the market. This form of participation can be initiated by manufacturing companies themselves or by consumers [38]. Due to the increasing individualization of products, it is conceivable that concepts such as co-creation could be considered in the classification of digital platforms.

\section{A Taxonomy for Digital Platforms}

In the following, the taxonomy in Table 3 is derived based on the previously discussed dimensions in literature. Concerning the structure, it should be noted that the perspectives on the dimensions differentiated in the previous section are dynamic, and a clear assignment is not necessarily possible. At the beginning of the taxonomy development process, according to Nickerson et al. [14], a meta-characteristic is defined, which serves as a comprehensive basis for the selection of dimensions and characteristics. Since the meta-characteristic has a critical effect on the resulting taxonomy, the choice must be made carefully. Each feature should be a logical consequence of the meta feature [14]. For a general taxonomy of digital platforms within this study, we chose the meta-characteristic digital platform. Since platforms differ in their practical applications, a success plan for all types of platforms is not useful or achievable. Instead, a useful first step towards a classification is to decide which dimensions offer sufficient distinctive features to justify a classification category [31].

Within the technological perspective as the first category, some dimensions and characteristics are of particular importance in distinguishing digital platforms. One dimension is platform access or openness [1]. For example, the dimension of openness at the user level of the authors Ondrus et al. [30] corresponds to the access to infrastructure as used by Blaschke et al. [4]. The authors Kazan et al. [19] have also described access to value-adding architectures and have used the characteristics directly, indirectly, and openly for this purpose. With regard to platform access, this work is oriented in particular to the division of Ondrus et al. [30] into provider access, user access and technology access. The characteristics open and closed are used for clarification. Furthermore, the type of pricing mechanisms is relevant for differentiation. 
Table 3. Taxonomy for Digital Platforms

\begin{tabular}{|c|c|c|c|c|c|}
\hline Category & Dimension & Characteristics & & & \\
\hline Technological & provider access & open & closed & & \\
\hline perspective & user access & open & closed & & \\
\hline & technology access & open & closed & & \\
\hline & pricing mechanisms & fixed & variable & & \\
\hline $\begin{array}{l}\text { Economic } \\
\text { perspective }\end{array}$ & $\begin{array}{l}\text { geographical scope } \\
\text { ownership } \\
\text { control }\end{array}$ & $\begin{array}{l}\text { global } \\
\text { intermediary } \\
\text { centralized }\end{array}$ & $\begin{array}{l}\text { national } \\
\text { buyer } \\
\text { decentralized }\end{array}$ & seller & coalition \\
\hline & value proposition & cost efficiency & emotional value & social value & \\
\hline & transaction content & product & service & & \\
\hline & transaction type & online & offline & & \\
\hline & market orientation & buyer & seller & impartial & \\
\hline & primary revenue source & buyer & seller & third party & \\
\hline & platform type & social media platform & mobile operating system & payment platform & peer-to-peer platform \\
\hline Socio-cultural & user constellation & B2B & B2C & $\mathrm{C} 2 \mathrm{C}$ & \\
\hline perspective & relationship level & long term & short term & & \\
\hline & participation mechanism & existing & non-existing & & \\
\hline
\end{tabular}

Different authors (e.g., $[10,34])$ divided between fixed and variable, which is adopted in this taxonomy. We assigned this dimension to the technological perspective due to the focus on the technological implementation of pricing mechanisms.

A second category, the economic perspective, includes the dimension geographical scope of a platform, based on Täuscher and Laudien [34], which indicates the scope of the customer target groups. In this case, however, the characteristics globally and nationally are used for increased distinctiveness. Here, national signifies a range limited to the country of the company's headquarters. Another critical dimension is the ownership of a platform company. The authors Soh and Markus [32], as well as Movahedi et al. [10], similarly considered these. Intermediary, buyer, seller, and coalition are used as characteristic values for this. The emergence of digital peer-to-peer platforms such as Uber or Airbnb has created a so-called sharing economy. Competition here is no longer characterized by control of the value chain, but rather how the generative activities associated with a platform can be attracted [1]. Nevertheless, digital platforms also occur in the form of electronic marketplaces, making it essential to distinguish whether control is centralized, by the platform operator, or decentralized, distributed among several members [2]. The dimension value proposition, the value perceived by the user, has been defined by Täuscher and Laudien [34] using comprehensible characteristics. We applied these to the taxonomy in terms of cost efficiency, emotional value, and social value. Some authors [29] have categorized the maturity of the revenue model in this respect, which we did not include because of lacking measurably. Some studies conclude that low-cost products that are easy to describe and experienced by the consumer are best suited for online buying and selling [22]. A frequently used dimension to distinguish between electronic markets is the type of product or service [25]. This is also considered useful for a general taxonomy. Therefore, we use it as a dimension of transaction content with the characteristics product and service [34]. In this context, the authors have also defined the transaction type as a dimension that clearly shows whether a transaction is carried out online or offline. According to Movahedi et al. [10], the platform can be oriented towards sellers or buyers, or it can adopt a neutral position. The market orientation of a platform may lead to distortion. This is also strongly linked to the primary revenue source of a platform, which may include buyers, sellers, or third parties. We distinguish the four platform types social media platforms, mobile operating systems, payment platforms, and peer-to-peer platforms mentioned by Blaschke et al. [4] to subdivide digital platforms at a high level of abstraction.

The third category covers the socio-cultural perspective. User constellation identifies the actors involved in transactions amongst each other. The characteristic values $\mathrm{B} 2 \mathrm{~B}, \mathrm{~B} 2 \mathrm{C}$, and $\mathrm{C} 2 \mathrm{C}$ are used for this purpose. According to the findings of this research, these are the three most frequent user constellations. Nevertheless, it should be noted that there may be other constellations, including the government, as user. The relationship level can also be an essential criterion for the general differentiation of digital platforms in terms of time. Thus, long-term relationships can e.g., be pursued by social media platforms, whereas electronic markets can maintain a comparatively short relationship for low-priced articles. It can be assumed that a long-term relationship orientation can generate more trust among digital platform users. From a technological point of view, the literature shows that certain website functionalities lead to trusting views [28]. Consumer emotions are important for companies because a current mood predicts future behavior. Mood analysis has become particularly important in the age of Big Data because, for example, social media offer marketers an unprecedented opportunity to 
monitor consumer sentiment regularly [26]. To this end, Täuscher and Laudien [34] have examined an evaluation system of platforms. The co-creation and participation mechanism mentioned in the previous chapter can also play an important role in the context of trust. This study combines these approaches in the taxonomy, whether platform users can basically participate in terms of a rating system that is available on the platform side or utilizing co-creation.

\section{Conclusion}

Researchers have already distinguished a variety of digital platform types from different perspectives. Nevertheless, little research effort has been made to address dimensions and features that contribute to the general differentiation of digital platforms. Our taxonomy represents an attempt to comprehensively classify digital platforms based on a conceptual taxonomy development approach. First, this paper has examined different focuses on classification schemes regarding digital platforms. Our work has shown that some approaches consider different classification dimensions. According to the findings of this literature review, economical and technological perspectives are addressed most frequently. Dimensions such as platform openness or the value proposition of a platform have often been identified in classification approaches. On this basis, RQ1 targets to select and deduce dimensions that have definite characteristics of digital platforms, which we transferred to a general taxonomy for the classification of digital platforms to answer RQ2. This taxonomy covers technological, economic as well as socio-cultural aspects of digital platforms.

However, there are some limitations in this paper. In particular, it does not provide statistical information on which features occur in which quantity. These could be investigated to define archetypes. Furthermore, this taxonomy is based on a limited number of relevant articles and does only include articles defining dimensions or characteristics. Ensuring the conciseness criterion, we only included the most essential dimensions and characteristics. Nevertheless, regarding robustness, this work has used a certain number of differentiation criteria. Especially from a technology point of view, other dimensions going beyond platform access and e.g., differentiating the technology used could be included. The taxonomy does have an explanatory and general character and does not cover each detail for clarity. Further research may extend the scope of articles of organizational research as well as keywords within the search term. For example, terms such as "two-sided" or "multi-sided" could be used concerning the characteristics of digital platforms. Also, the terms "architecture*" or "framework*" or "characteristic*" could be added for taxonomies as a classification method. From a socio-cultural perspective, it appears that trust can be attributed a certain importance in the context of digital platforms. Concerning the concept matrix (cf. Table 2), future research should focus on $\mathrm{B} 2 \mathrm{C}$ and $\mathrm{C} 2 \mathrm{C}$ platforms as well as the dimensions market distortion and user participation. In summary, the comprehensive classification developed in this work provides a basis for further research activities, especially to validate, refine and extend it to clarify its completeness.

\section{Acknowledgements}

This study is based upon work funded by the German Federal Ministry of Education and Research (BMBF) within the program "Innovations for Tomorrow's Production, Services, and Work" (funding number 02K16C100) and implemented by the Project Management Agency Karlsruhe (PTKA).

\section{References}

[1] M. De Reuver, C. Sørensen, and R. C. Basole, "The Digital Platform: A Research Agenda," Journal of Information Technology, vol. 33, no. 2, pp. 124-135, 2018.

[2] A. Ghazawneh and O. Henfridsson, "A Paradigmatic Analysis of Digital Application Marketplaces," Journal of Information Technology, vol. 30, no. 3, pp. 198-208, 2015.

[3] J. Y. Bakos, "A Strategic Analysis of Electronic Marketplaces," Management Information Systems Quarterly, vol. 15, no. 3, pp. 295-310, 1991.

[4] M. Blaschke, K. Haki, S. Aier, and R. Winter, "Taxonomy of Digital Platforms: A Platform Architecture Perspective," in International Conference on Wirtschaftsinformatik, pp. 572-586, 2019.

[5] L. D. Thomas, E. Autio, and D. M. Gann, "Architectural Leverage: Putting Platforms in Context," Academy of Management Perspectives, vol. 28, no. 2, pp. 198-219, 2014.

[6] A. Gawer, "Bridging Differing Perspectives on Technological Platforms: Toward an Integrative Framework," Research Policy, vol. 43, no. 7, pp. 1239-1249, 2014.

[7] G. G. Parker and M. W. Van Alstyne, "Two-Sided Network Effects: A Theory of Information Product Design," Management Science, vol. 51, no. 10, pp. 1494-1504, 2005.

[8] Y. Yoo, O. Henfridsson, and K. Lyytinen, "Research Commentary - The New Organizing Logic of Digital Innovation: An Agenda for Information Systems Research," Information Systems Research, vol. 21, no. 4, pp. 724-735, 2010.

[9] K. Reimers, X. Guo, and M. Li, "Beyond Markets, Hierarchies, and Hybrids: An Institutional Perspective 
on IT-enabled Two-sided Markets," Electronic Markets, vol. 29, no. 2, pp. 287-305, 2019.

[10] B. Movahedi, K. M. Lavassani, and V. Kumar, "E-Marketplace Emergence: Evolution, Developments and Classification," Journal of Electronic Commerce in Organizations, vol. 10, no. 1, pp. 14-32, 2012.

[11] A. Tiwana, B. Konsynski, and A. A. Bush, "Research Commentary - Platform Evolution: Coevolution of Platform Architecture, Governance, and Environmental Dynamics," Information Systems Research, vol. 21, no. 4, pp. 675-687, 2010.

[12] S. Matook, "Measuring the Performance of Electronic Marketplaces: An External Goal Approach Study," Decision Support Systems, vol. 54, no. 2, pp. 1065-1075, 2013.

[13] H. M. Cooper, "Organizing Knowledge Synthesis: A Taxonomy of Literature Reviews," Knowledge in Society, vol. 1, no. 1, pp. 104-126, 1988.

[14] R. C. Nickerson, U. Varshney, and J. Muntermann, "A Method for Taxonomy Development and its Application in Information Systems," European Journal of Information Systems, vol. 22, no. 3, pp. 336-359, 2013.

[15] J. Webster and R. T. Watson, "Analyzing the Past to Prepare for the Future: Writing a Literature Review," MIS Quarterly, vol. 26, no. 2, pp. xiii - xxiii, 2002.

[16] J. vom Brocke, A. Simons, B. Niehaves, K. Riemer, R. Plattfaut, and A. Cleven, "Reconstructing the Giant: On the Importance of Rigour in Documenting the Literature Search Process," European Conference on Information Systems, no. 161, pp. 1-12, 2009.

[17] Association for Information Systems, "Senior Scholars' Basket of Journals," https://aisnet.org/? SeniorScholarBasket, accessed on 10.05.2020.

[18] VHB, "VHB-Jourqual 3," https://www.vhbonline.org/ vhb4you/vhb-jourqual/vhb-jourqual-3/gesamtliste, accessed on 12.06.2020.

[19] E. Kazan, C. W. Tan, E. T. Lim, C. Sørensen, and J. Damsgaard, "Disentangling Digital Platform Competition: The Case of UK Mobile Payment Platforms," Journal of Management Information Systems, vol. 35, no. 1, pp. 180-219, 2018.

[20] R. Alt, M. A. Cäsar, and J. U. Grau, "Collaboration in the Consumer Product Goods Industry - Analysis of Marketplaces," in European Conference on Information Systems, no. 92, pp. 582-595, 2002.

[21] C. E. Barbosa, V. J. Epelbaum, M. Antelio, J. Oliveira, and J. M. De Souza, "Crowdsourcing Environments in e-Learning Scenario: A Classification based on Educational and Collaboration Criteria," IEEE International Conference on Systems, Man, and Cybernetics, pp. 687-692, 2013.

[22] E. M. Daniel, J. Hoxmeier, A. White, and A. Smart, "A Framework for the Sustainability of e-Marketplaces," Business Process Management Journal, vol. 10, no. 3, pp. 277-289, 2004.

[23] S. X. Duan, H. Deng, and F. Luo, "An Integrated Approach for Identifying the Efficiency-oriented Drivers of Electronic Markets in Electronic Business," Journal of Enterprise Information Management, vol. 32, no. 1, pp. 60-74, 2019.

[24] A. W. Eigenraam, J. Eelen, A. van Lin, and P. W. Verlegh, "A Consumer-based Taxonomy of Digital Customer Engagement Practices," Journal of Interactive Marketing, vol. 44, pp. 102-121, 2018.
[25] A. M. Fairchild, P. M. Ribbers, and A. O. Nooteboom, "A Success Factor Model for Electronic Markets: Defining Outcomes based on Stakeholder Context and Business Process," Business Process Management Journal, vol. 10, no. 1, pp. 63-79, 2004.

[26] A. Gopaldas, "Marketplace Sentiments," Journal of Consumer Research, vol. 41, no. 4, pp. 995-1014, 2014.

[27] S. Grabner-Kraeuter, "The Role of Consumers' Trrust in Online-Shopping," Journal of Business Ethics, vol. 39, pp. 43-50, 2002.

[28] P. Gupta, M. S. Yadav, and R. Varadarajan, "How Task-Facilitative Interactive Tools Foster Buyers' Trust in Online Retailers: A Process View of Trust Development in the Electronic Marketplace," Journal of Retailing, vol. 85, no. 2, pp. 159-176, 2009.

[29] C. P. Holland and M. Gutiérrez-Leefmans, "A Taxonomy of SME E-Commerce Platforms Derived," International Journal of Electronic Commerce, vol. 22, no. 2, pp. 161-201, 2018.

[30] J. Ondrus, A. Gannamaneni, and K. Lyytinen, "The Impact of Openness on the Market Potential of Multi-sided Platforms: A Case Study of Mobile Payment Platforms," Journal of Information Technology, vol. 30, no. 3, pp. 260-275, 2015.

[31] H. Sharifi, D. F. Kehoe, and J. Hopkins, "A Classification and Selection Model of e-Marketplaces for Better Alignment of Supply Chains," Journal of Enterprise Information Management, vol. 19, no. 5, pp. 483-503, 2006.

[32] C. Soh and M. L. Markus, "Business-to-Business Electronic Marketplaces: A Strategic Archetypes Approach," in International Conference on Information Systems, no. 2002, pp. 835-845, 2002.

[33] C. Standing, P. E. Love, R. Stockdale, and D. Gengatharen, "Examining the Relationship between Electronic Marketplace Strategy and Structure," IEEE Transactions on Engineering Management, vol. 53, no. 2, pp. 297-311, 2006.

[34] K. Täuscher and S. M. Laudien, "Understanding Platform Business Models: A Mixed Methods Study of Marketplaces," European Management Journal, vol. 36, no. 3, pp. 319-329, 2018.

[35] T. Verhagen, S. Meents, and Y. H. Tan, "Perceived Risk and Trust Associated with Purchasing at Electronic Marketplaces," European Journal of Information Systems, vol. 15, no. 6, pp. 542-555, 2006.

[36] Y. Wang, Z. Qu, and B. Tan, "How Do Assurance Mechanisms Interact in Online Marketplaces? A Signaling Perspective," IEEE Transactions on Engineering Management, vol. 65, no. 2, pp. 239-251, 2018.

[37] Y. Yu and J. Ramaprasad, "Engagement on Digital Platforms: A Theoretical Perspective," International Conference on Information Systems, no. 40, pp. 1-8, 2019.

[38] V. Zwass, "Co-creation: Toward a Taxonomy and an Integrated Research Perspective," International Journal of Electronic Commerce, vol. 15, no. 1, pp. 11-48, 2010.

[39] J. S. Leong, C.; Pan, S. L.; Leidner, D. E.; Huang, "Platform Leadership: Managing Boundaries for the Network Growth of Digital Platforms," Journal of the Association for Information Systems, vol. 20, no. 10, pp. 1531-1565, 2019. 